Carlos

Montemayor:

humanista

contemporáneo

\section{Natalio Hernández}

C arlos Montemayor fue un escritor versátil y polifacético, un humanista contemporáneo, un tolteca; esto es, un artista, un creador.

Su trayectoria profesional como poeta y traductor de los clásicos griegos y latinos de la literatura universal le permitió desarrollar la sensibilidad necesaria para que, en gran medida, dedicara los últimos 20 años de su vida al desarrollo de la literatura en las lenguas originarias de México en particular y de América en general.

Carlos y yo coordinamos el Primer Encuentro Nacional de Escritores en Lenguas Indígenas, en octubre de 1990. Esta reunión detonó un movimiento literario mediante la creación de la Asociación de Escritores en Lenguas Indígenas (1993) y el Programa Nacional de Lenguas y Literatura Indígenas del entonces Consejo Nacional para la Cultura y las Artes (1994).

El desarrollo de estos dos proyectos ha contribuido a que México sea en la actualidad un referente mundial en materia de literatura contemporánea en lenguas originarias. Esto se confirmó con la realización del Primer Encuentro Mundial de Poesía de los Pueblos Indígenas: Voces de Colores para la Madre Tierra, que se inauguró en la sala principal del Palacio de Bellas Artes en octubre de 2016.

Con todo ello podemos afirmar que el mayor impacto social y cultural que tuvo Carlos Montemayor, con su obra, fue haber contri- buido a que las lenguas nacionales de nuestro país trascendieran de su ámbito local y comunitario hacia los diversos espacios culturales y académicos de México y de América.

Además, Carlos mostró el arte que se preserva en las lenguas originarias de México, las cuales cuentan con más de cinco mil años de antigüedad, como lo afirman los lingüistas, en comparación con la lengua española, que tiene mil años de existencia.

En reiteradas ocasiones Montemayor afirmó que México, como nación, no se puede explicar ni entender si no se considera este acervo lingüístico y literario que se preserva en la memoria ancestral de los pueblos y en muchos documentos históricos.

Afortunadamente, varias instituciones académicas y culturales han abierto espacios para el estudio, el desarrollo y la difusión de las lenguas y la literatura de los idiomas mexicanos. De manera destacada, cabe mencionar el Festival de Poesía Las Lenguas de América Carlos Montemayor, de la UNAM, en homenaje a su creador, que se celebra de manera bianual desde 2004.

Previo a su fallecimiento, Montemayor señaló que uno de los acontecimientos más importantes de este siglo es la emergencia de los escritores en las lenguas originarias de México. "En adelante", dijo,

ya no serán los antropólogos, los lingüistas y los indigenistas quienes hablen por los pueblos indígenas. Serán ellos mismos, a través de sus poetas y escritores, los que nos dirán quiénes son, de dónde vienen, qué piensan, qué sienten, cuáles son sus problemas, sus aspiraciones y sus proyectos de vida.

Sobre esta materia podemos señalar algunas de sus obras: La literatura actual en las lenguas indígenas de México (Universidad Iberoamericana); el Diccionario del náhuatl en el español de México (UNAM); el recuento de poesía $L a$ voz profunda. Antología de literatura mexicana en lenguas indígenas (UNAM), así como la colección Letras mayas contemporáneas (INI-Sedesol), entre otras. Mi maestro Miguel León-Portilla, en el obituario que escribió con motivo de su fallecimiento en 2010, expresó: "Carlos Montemayor, el hombre del Renacimiento, trabajó sin descanso en pro de los pueblos indígenas y en el enriquecimiento de la cultura mexicana".

Con todo lo anterior, podemos decir que la obra literaria de Montemayor estará vigente durante todo el siglo XXI, toda vez que este es y será el siglo de la diversidad, del diálogo de las culturas y de las lenguas; en suma, del diálogo de las civilizaciones de todos los pueblos del mundo.

En la introducción a la antología Literatura indígena, ayer y hoy, (Culturas Populares-Conaculta), que se publicó con motivo del Primer Encuentro Nacional de Escritores en Lenguas Indígenas, celebrado en Ciudad Victoria, Tamaulipas en octubre de 1990, Carlos expresó:

En todos los pueblos del mundo el idioma es la memoria del paisaje, de la historia, de la divinidad a que aspiran los hombres. Es la voz que crece como otros árboles y otros ríos en la misma tierra en que los pueblos viven. Es la memoria de los combates ganados y perdidos. Es la misma fuerza que hace a los viejos seguir hablando con las mismas palabras que aprenden los niños...

Y no hay un idioma superior a otro. La lengua maya es tan importante como la inglesa, la francesa, la alemana, o la española; como el náhuatl, el purépecha, el otomí, porque

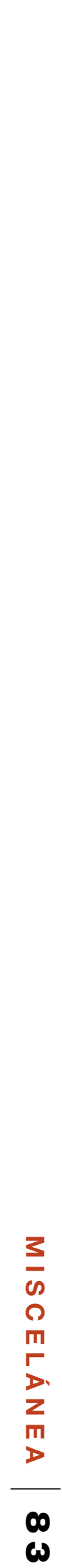




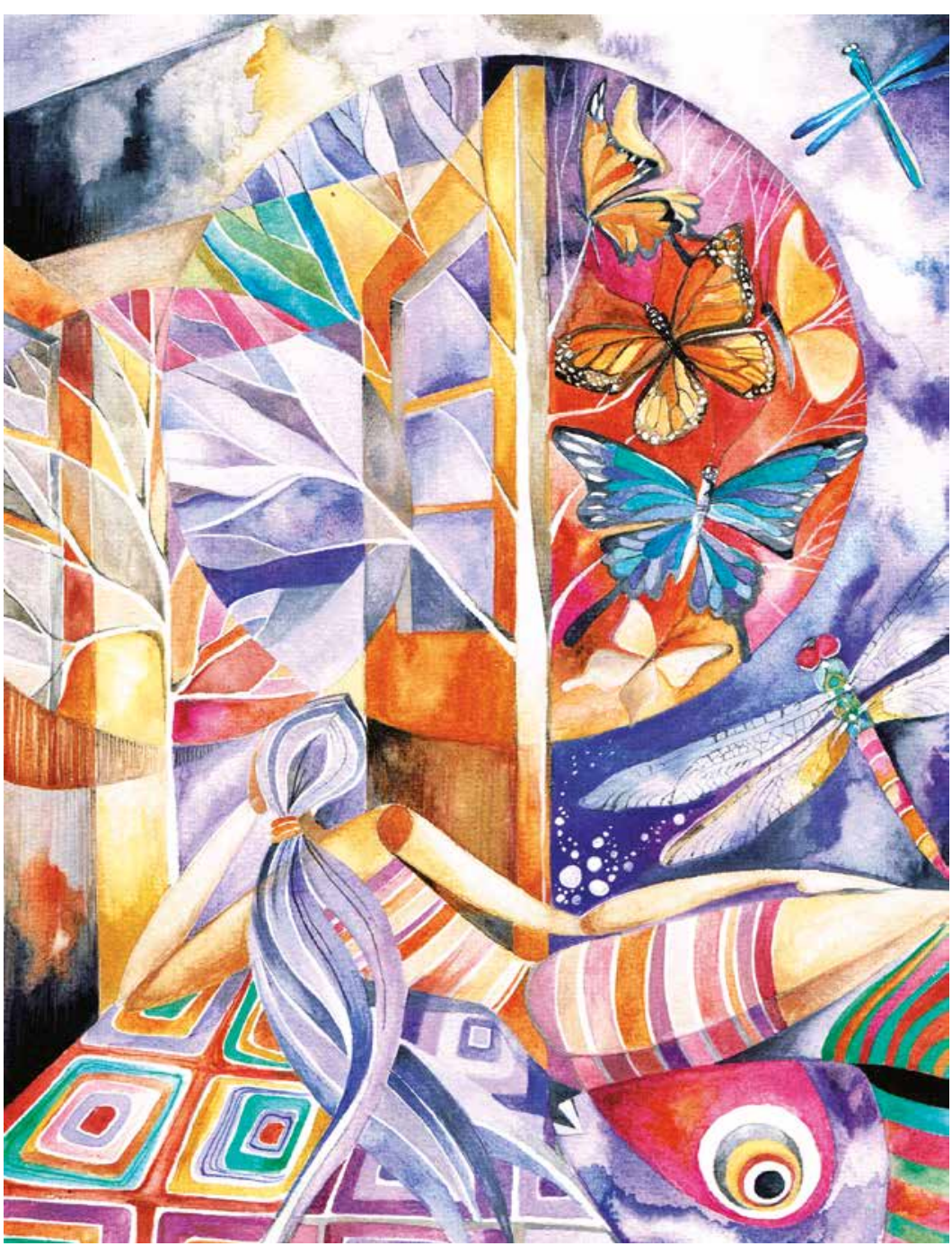

Alas. De la serie Universos internos

todas son iguales. Y una de nuestras grandes riquezas son los idiomas. Una riqueza que debemos defender porque son el alma de todos los pueblos que viven en México...

En los momentos actuales en que un sector de la elite mexicana, piensa que enterrando el pasado indígena podemos ser un país fuerte y desarrollado, debemos, creo yo, retomar el pensamiento y los aportes de Carlos Montemayor. Durante su visita a China, muy próxima a la fecha de su fallecimiento, Carlos me comentó: "Natalio, ahora entiendo mejor a los chinos, ellos jamás han renunciado a su acervo lingüístico y cultural milenario. Lo único que hacen, en cada época, es renovarlo. Por eso han logrado un desarrollo con identidad y están a la vanguardia de la economía mundial”.

Con motivo del 70 aniversario de su nacimiento (13 de junio de 1947), se realizaron homenajes en distintos espacios culturales y académicos, muy merecidos porque su pensamiento y su obra, creo yo, no deben morir. Él nos enseñó que debemos maravillarnos de la sinfonía de voces y de la música contenida en nuestras lenguas mexicanas, que son más de sesenta y cinco. Nos enseñó también a disfrutar la música y el canto; él mismo fue un excelente músico y tenor, como se puede leer en el libro El canto del aeda. Testimonios de Carlos Montemayor, del periodista Pablo Espinosa. Fue un sibarita del vino y la comida. En fin, fue un hombre que amó la vida, las raíces antiguas y profundas de México; amó "la flor y el canto": in xochitl in cuicatl.

Como corolario de estas palabras, en la conmemoración del 70 aniversario de su nacimiento quiero recordar que conocí a Carlos en 1980, en una mesa redonda sobre el tema de los pueblos indígenas, en la Escuela para Extranjeros de la UNAM. Hacíamos un perfecto contraste: él vestía un impecable traje oscuro, con un pañuelo rojo en el bolsillo del saco y una elegante corbata; me lo imaginaba como un caballero inglés. Por mi parte, iba de huaraches, pantalón de mezclilla, camisa de manta, un pañuelo rojo en el cuello y pelo largo. En ese tiempo, yo militaba en el movimiento indígena, con un discurso muy demandante, $y$ eso fue, creo yo, lo que a Carlos le llamó la atención. Desde entonces caminamos juntos hasta el día de su muerte. Primero fue mi compañero; después, mi amigo, maestro y colega $y$, finalmente, mi hermano. La poesía y la lucha por el reconocimiento y la reivindicación de nuestros pueblos nos hermanó para siempre.

Ipampa inon, ma nochipa tlachixto Carlos Montemayoripan ipan to yolo ihuan to tlahlamiquilis: Por eso, creo yo, Carlos Montemayor debe vivir para siempre en nuestros corazones y en nuestra mente. LPyH

- Natalio Hernández es profesor de Literatura en Lenguas Indígenas en la UNAM, miembro de la Academia Mexicana de la Lengua y autor de libros de poesía y ensayo. 